\title{
Fluctuating asymmetry, spot asymmetry and inbreeding depression in the sexual coloration of male guppy fish
}

\author{
LETITIA SHERIDAN \& ANDREW POMIANKOWSKI* \\ Department of Biology, University College London, 4 Stephenson Way, London NW1 2HE, U.K. and \\ *Wissenschaftskolleg zu Berlin, Wallotstrasse 19 D-14193 Berlin, Germany
}

\begin{abstract}
This paper tests the hypothesis that fluctuating asymmetry in exaggerated sexual traits is a sensitive indicator of genetic stress. Inbreeding was used to create genetic stress in two populations of male guppies collected from the Aripo and Paria river basins in Trinidad. Fluctuating asymmetry in the size of carotenoid, melanin and iridescent pigments did not differ between inbred and control males. There was also no difference in spot asymmetry. The lack of response was not caused by inbreeding having no effect on the male phenotype. Inbred Aripo males had less melanin pigment, fewer melanin spots and fewer iridescent subspots, and Paria males had less carotenoid pigment. Our results show that sexual coloration in guppies is sensitive to genetic stress caused by inbreeding, but they provide no support for the hypothesis that genetic stress is reflected particularly well by the degree of fluctuating asymmetry. The different response to inbreeding in the two populations is interesting. There was inbreeding depression in the area of carotenoid pigment in the Paria population, in which this characteristic is known to influence female mate choice, whereas there was no inbreeding depression in the Aripo population, in which females show no detectable preference for carotenoid pigments.
\end{abstract}

Keywords: female preference, fluctuating asymmetry, guppy, inbreeding depression, mate choice, sexual selection.

\section{Introduction}

It is widely thought that fluctuating asymmetry (FA) is a sensitive indicator of developmental stress (Soulé, 1982; Parsons, 1990; Møller \& Pomiankowski, 1993). Both genetic (e.g. inbreeding, hybridization, spread of new mutants) and environmental (e.g. $\mathrm{pH}$, temperature, pollutants) stresses are thought to lead to increased FA. This has lead to the promotion of FA as a useful measure of wellbeing at both the individual and population levels and the proposal that FA may be a useful proxy for fitness (Clarke, 1995).

The recent revival of interest in fluctuating asymmetry results in large part from novel applications in sexual selection. In a number of papers Møller and others have argued that exaggerated secondary sexual characters differ from other traits as they (i) have much higher mean levels of FA and (ii) often

\footnotetext{
*Correspondence: A. Pomiankowski, Department of Biology, University College London, 4 Stephenson Way, London NW1 2HE, U.K. E-mail: ucbhpom@ucl.ac.uk
}

show a negative correlation between FA and trait size (Møller, 1990; Møller \& Höglund, 1991). The latter relationship is taken as evidence supporting the 'good genes' hypothesis. It has been suggested that males with larger sexual traits are high-quality individuals because they appear able to absorb the costs of producing larger ornaments without loss of developmental control. This hypothesis is particularly interesting as it has been shown that females prefer males with symmetric sexual traits (Møller, 1992), a result confirmed in model systems (Swaddle \& Cuthill, 1994a,b).

In this study we have addressed a more basic consideration. Does genetic stress caused by inbreeding elevate the degree of FA in sexual traits? Inbreeding is expected to cause stress by increasing the frequency of homozygous, deleterious, recessive alleles (Charlesworth \& Charlesworth, 1987). Evidence that inbreeding increases FA in non-sexual traits is inconsistent. Several studies have reported that population-level FA correlates positively with homozygosity in natural populations (Soulé, 1979; 
Leary et al., 1984) and is higher under controlled inbreeding (Mather, 1953; Reeve, 1960). However, the few carefully controlled and well-replicated experiments have failed to show any association between inbreeding and FA (Clarke et al., 1992; Fowler \& Whitlock, 1994). None of these experiments has examined genetic stress in sexual traits. Sexual traits are of interest because they are often highly exaggerated and costly to produce (Andersson, 1994) and thus might be more sensitive to genetic stress.

The effect of inbreeding was studied in the sexual coloration of male Trinidadian guppies. These fish are well suited for this investigation as males have prominent sexual pigments, which females use in mate-choice decisions (Endler, 1980). Furthermore, male colour patterns and female mate preference vary geographically (Houde \& Endler, 1990) allowing inbreeding effects to be compared between different populations. The area of carotenoid, melanin and iridescent pigments was calculated for each side of the body. We also counted the number of discrete colour spots and noted whether spots were located in the same or different positions on each side. This allowed FA, mean area, spot number and spot asymmetry to be compared between inbred and control males.

Three hypotheses were explicitly addressed. First, did inbreeding lead to an increase in FA in male sexual colour patterns? Secondly, was FA a more sensitive measure of inbreeding than other phenotypic measures? This question was addressed by measuring whether increases in FA caused by inbreeding were more easily detected than reductions in the size of male colour pigment area, reductions in the number of colour spots (i.e. types of inbreeding depression) or changes in the distribution of colour spots on left and right sides (i.e. spot asymmetry). Thirdly, were male traits that are preferred by females more sensitive to inbreeding than other sexual traits? This hypothesis was tested by comparing the effects of inbreeding in two guppy populations that have distinct male colour patterns and distinct female mate preferences.

\section{Materials and methods}

\section{Origin of populations}

Guppies used in these experiments were descendants of individuals of mixed sexes and ages collected from the wild in Trinidad in 1992. The guppies were collected from two different sites, the lower Aripo and Paria rivers. These rivers flow down opposite sides of the Northern Range mountains in Trinidad and have been separated for approximately 250000 years (Fajen \& Breden, 1992). Large samples $(200+$ individuals $)$ were collected from each river so as to maintain genetic variation in founding the laboratory stock populations. The populations were maintained in $22-\mathrm{L}$ aquaria under a 12:12 h light-dark regimen, and fed Tetramin tropical fish food ad libitum.

Each population is typified by different male sexual displays and corresponding female mate preference (Houde, 1988a). Paria males (low visual predation river) have very bright carotenoid coloration, much melanin pigment but little iridescent pigment. Paria females show strong preference for males with more carotenoid (Houde, 1988a; Houde \& Endler, 1990). In contrast, Aripo males (high visual predation river) have very little carotenoid, about the same amount of melanin but much greater iridescent pigment. Aripo females do not show any preference for carotenoid pigments (Houde, 1988b). Aripo females prefer different males but it has not been shown which elements in the male display are the most important (Houde, 1988b).

\section{Inbreeding scheme}

Experimental populations were set up after 5-6 generations in the laboratory. Several virgin females were isolated with single males. Individual broods were collected. Male offspring were removed as soon as there was evidence of sexual differentiation. Offspring were collected over 8 weeks. This collection period was deliberately kept short so that the offspring used in the experiments were a cohort of similar ages.

Pairs of brothers were used as sires, one for the inbred line, the other for a matched control. Most male colour pattern genes of large effect are Y-linked (Houde, 1988a). Thus, standardizing the Y chromosome across pairs of lines limited the effect of inbreeding to autosomal genes. Each male was placed in a separate aquarium and mated to five virgin females. Males and females were matched for age ( 6 months). In the inbred line, the five females were full-sibs. In the control line, the five females were also full-sibs but from an unrelated family. A total of six matched lines were established, four from the Aripo population and two from the Paria. The fecundity of Paria females was low so the breeding scheme was repeated for a second generation. Further pairs of males were selected, one from each inbred and control line. Inbred males were mated to five sisters and control males were mated 
to five sisters from an unrelated brood. The design using five sisters to each male was intended to remove dam-family effects between unrelated females [shown to be strong in one case (Nicoletto, 1995) and small in another (Houde, 1992)]. In most cases, only one foundress in each line produced offspring, so this concern turned out to be of less relevance. The inbreeding coefficients in the inbred lines were $F=0.25$ in Aripo and $F=0.25-0.31$ in Paria.

\section{Data collection}

All offspring of inbred and control males were photographed on both sides at 14 weeks. At this age, male colour patterns had developed. Males were photographed at the same age as coloration continues to develop through time (Endler, 1978). Photography was carried out under standard lighting conditions with a Kodak 18 per cent reflectance grey background. Each guppy was placed in a small plastic spectrophotometer cuvette that had optically clear sides. Anaesthetic was not used as it alters colour patterns (Endler, 1978; Reynolds et al., 1993). Each fish was confined for a maximum of $30 \mathrm{~s}$ before release, and all fish were removed from their tanks for the same total amount of time to standardize the effect of stress on the appearance of pigments (which are partially under voluntary control).

These images were transferred to a Macintosh computer using a black and white CCD camera. Lengths and areas were measured using NIH Image. The resolution power of this system was limited by the pixel dimension of the screen (average fish dimensions $547 \times 210$ pixels). Boundaries of colour areas were visible on the captured black and white images. Where contrast was poor the boundaries were pinpointed using the original colour photograph.

Several morphological characters and secondary sexual characters were measured in each male guppy. Morphological characters measured were (Fig. 1): total length, body length, maximum depth, total area (including the tail fin), body area (excluding the tail fin), dorsal fin area, caudal fin area and gonopodial length. One paired morphological trait was measured, the length of 10 dorsal scales (on left and right sides). The measurement of male colour pattern was broken down into pigment groups: carotenoid (orange), melanin (black) and iridescent (purple, green, yellow, blue and silver). The total area of the pigment groups on each side of the body was estimated. The boundaries between different

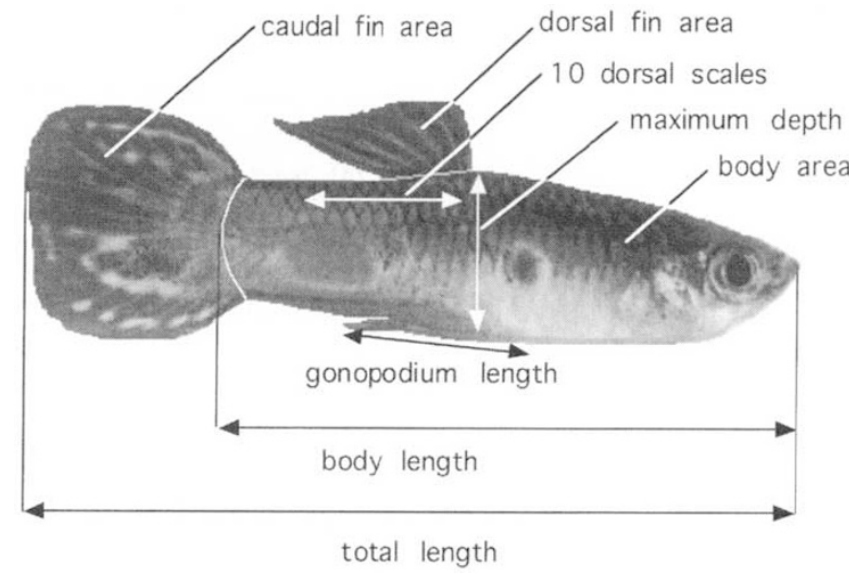

Fig. 1 Standard morphological measurements of a male guppy.

iridescent colours were too faint to allow each colour area to be measured separately. Pigment areas on the tail and dorsal fin were ignored as they are visible from both sides and thus cannot be considered as paired characters. Every measurement was performed twice to estimate measurement error. In addition the number and position of spots on each body side was recorded. All measurements were made by L. S.

\section{Measuring size}

All sexual and morphological traits were examined for evidence of inbreeding depression. This provides a useful comparison with the effects of inbreeding on FA. Mean trait size was compared between inbred and control lines for each population. All of the morphological traits were normally distributed and thus needed no transformation. The colour pigment areas had a skewed distribution, with smaller values being rare. Left and right measures were square-root transformed after the Box-Cox test revealed that this was an appropriate power transformation. Transformed measures were normally distributed. No transformation was required for the left and right dorsal scale measurements. Data from the different lines were pooled and analysed in an ANOVA taking out the effect of line.

\section{Measuring fluctuating asymmetry}

Fluctuating asymmetry of the three colour pigment groups $(\sqrt{ }$ transformed) and the single paired morphological trait (10 dorsal scales) was compared 
between the inbred and control populations for the Paria and Aripo populations. Fluctuating asymmetry was estimated using a two-way, mixed-model ANOVA $($ sides $=$ random, $\quad$ treatment $=$ fixed $)$, with two measurements of each side (Palmer \& Strobeck, 1986). The ANOVA measures population FA as the variance between left and right sides. It also allows directional asymmetry and measurement error to be estimated.

Individual signed asymmetry scores (mean $\mathrm{R}$ mean L) were also examined for the four traits in each population. Individuals were excluded if they lacked any pigment on left or right sides. There was no evidence that the mean level of the remaining signed asymmetry differed from zero. The Kolmogorov-Smirnov test revealed no evidence for antisymmetry, that is broad-peaked or bimodal departures from normality.

The colour pigment data were transformed in two ways to take account of possible confounding effects. To control for correlation with trait area, relative FA was estimated by dividing left and right measures by the mean trait area for each individual. To control for correlation with body area, \%FA was estimated by dividing measurements by the body area of each individual and taking a percentage. Transformed data were processed in the same way as before to derive population measures for relative FA and $\% \mathrm{FA}$. These transformations are justifiable when scaling exists. So we checked whether the unsigned asymmetry $(\mid$ mean $\mathrm{R}-$ mean $\mathrm{L} \mid)$ in each trait scaled linearly with mean trait area or body area, and whether these relationships intercepted at the origin (Cuthill et al., 1993).

\section{Measuring spot number and spot asymmetry}

The analysis of male guppy colour patterns was not as straightforward as the estimation of FA above suggests. A high proportion of male guppy pattern elements did not occur in the usual paired manner common to FA work. Colour pigments were concentrated into a variable numbers of spots. Spot shapes differed and sometimes spots were missing from one side (Fig. 2). Around half the males had one or more of their melanin or carotenoid spots missing or in totally different positions on the left and right sides.

There are no agreed techniques for the analysis of such variable patterns. We left out individuals that had missing spots from the analysis of FA and size. The amount of fluctuating asymmetry in individuals with missing spots can be several orders of magni-

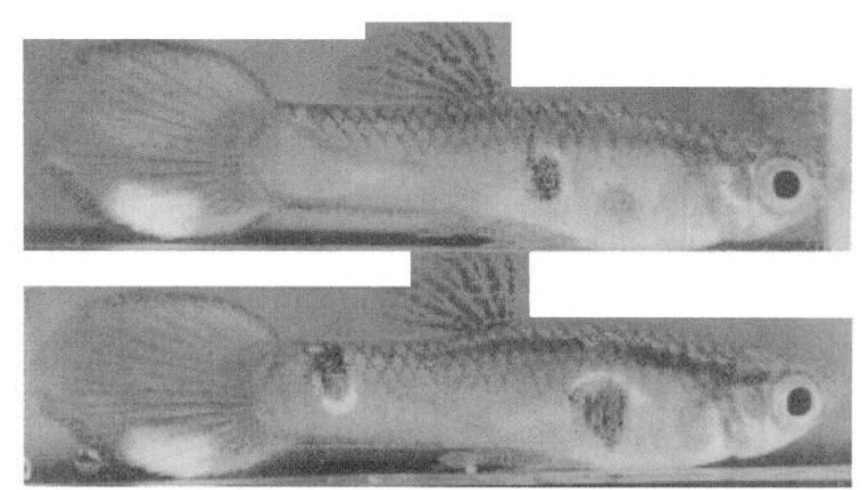

Fig. 2 Spot asymmetry was assessed in guppies by comparing right (upper) and left (lower) sides of an individual. This male has a different number of melanin spots on each side (two left and one right) and each spot is unmatched in terms of location.

tude greater than those with paired pigment spots. If such individuals had been included they would have severely distorted the analysis. Our estimate of population FA thus only relates to the small differences between left and right sides, and our measurement of size only relates to those individuals with pigment on both sides.

To bring individuals with missing spots into the analysis we compared the total spot number in inbred and control lines. This was carried out for each pigment colour on each side. We broke down iridescent pigment into its components, blue, yellow, green, purple and silver, and counted the total number of iridescent subspots and subcolours.

To quantify side variation in spot position and number we manipulated the computer pictures of the left and right sides so that they were aligned in the same direction (Fig. 2). A spot was scored as matched if it overlapped with a spot on the other side. Spots that did not overlap were scored as unmatched for the three pigments. In addition, for iridescent colours we repeated this analysis at the level of the component iridescent colours. We calculated the number of unmatched iridescent subspots and the number of unmatched iridescent subcolours (colours present on one side).

As the distribution of spot numbers was not normal and not continuous, measurements were treated as ordinal variables. Data from different lines were pooled and analysed using ordinal logistic regression, taking out the effect of line. All statistical analyses were carried out using JMP (SAS Institute, 1996).

(C) The Genetical Society of Great Britain, Heredity, 79, 515-523. 


\section{Results}

\section{Morphological characters}

There was only weak evidence of inbreeding depression in the morphological traits (Table 1). Control fish generally had larger trait values in the Aripo but the reverse was true in the Paria. Any relationship was obscured in part by the large variation between lines. The only significant inbreeding depression was in caudal fin area of the Aripo population. But given the large number of tests, this contrast was not significant after making a sequential Bonferroni adjustment (Sokal \& Rholf, 1995). In the Paria population there was no evidence of inbreeding depression.

\section{Directional asymmetry and measurement error}

There was no evidence of directional asymmetry for any pigment colour in either population. None of the comparisons of variance attributable to side compared with non-directional sources of variance was significant (all $P>0.05$; technique in Palmer \& Strobeck, 1986).

All measurements were carried out twice to allow measurement errors to be estimated. Measurement errors associated with pigment areas were small (mean $-<1$ percent). $F$-tests comparing the esti- mate of population FA to measurement error revealed that FA made a significant contribution to the variance observed (melanin, carotenoid and iridescent in both populations $P<0.05$ ). But measurement errors associated with the 10 dorsal scales were considerably larger (mean approximately 3 per cent). It was much harder to pinpoint accurately where scales began and ended. The estimate of population FA relative to the measurement error was not significant for 10 dorsal scales in the Aripo control $\left(F_{22,46}=1.196, P>0.05\right)$ or Paria control $\left(F_{18,38}=1.84, P>0.05\right)$ populations, so comparison of FA in dorsal scales between inbred and control populations was not possible.

\section{FA}

For none of the three colour patterns was there evidence that inbreeding increased FA (Table 2). This was true for both Paria and Aripo males. The lack of any increase in FA in inbred populations persisted when relative FA and \%FA were used (Table 2). Controlling for trait area was justified for melanin in Aripo males (positive relationship, $P=0.020$ ) and controlling for body area was justified for carotenoid in Aripo males (negative relationship, $P=0.035)$. All other relationships with

Table 1 Means and standard errors for morphological traits (untransformed data) in male guppies. All traits were normally distributed and comparison was made controlling for line, ${ }^{*} P<0.05$

\begin{tabular}{|c|c|c|c|c|c|c|}
\hline \multirow[b]{2}{*}{ Population } & \multirow[b]{2}{*}{ Measurement } & \multicolumn{2}{|r|}{ Inbred } & \multicolumn{2}{|r|}{ Control } & \multirow[b]{2}{*}{$P$} \\
\hline & & $N$ & mean $\pm \mathrm{SE}$ & $N$ & mean $\pm \mathrm{SE}$ & \\
\hline \multirow[t]{9}{*}{ Aripo } & Body length & 24 & $14.851 \pm 0.240$ & 22 & $14.996 \pm 0.175$ & 0.261 \\
\hline & Total length & 24 & $20.254 \pm 0.356$ & 22 & $20.554 \pm 0.236$ & 0.128 \\
\hline & Maximum depth & 24 & $3.553 \pm 0.048$ & 22 & $3.531 \pm 0.058$ & 0.993 \\
\hline & Gonopodial length & 24 & $3.523 \pm 0.085$ & 22 & $3.433 \pm 0.129$ & 0.506 \\
\hline & Caudal fin area & 24 & $19.188 \pm 0.734$ & 22 & $21.043 \pm 0.669$ & $0.044^{*}$ \\
\hline & Dorsal fin area & 24 & $4.779 \pm 0.296$ & 22 & $5.490 \pm 0.240$ & 0.142 \\
\hline & Body area & 24 & $41.551 \pm 1.211$ & 22 & $42.019 \pm 0.942$ & 0.329 \\
\hline & Total area & 24 & $65.477 \pm 1.862$ & 22 & $68.553 \pm 1.590$ & 0.099 \\
\hline & 10 dorsal scales & 24 & $4.188 \pm 0.077$ & 22 & $4.211 \pm 0.071$ & 0.571 \\
\hline \multirow[t]{9}{*}{ Paria } & Body length & 14 & $15.328 \pm 0.271$ & 19 & $14.882 \pm 0.309$ & 0.268 \\
\hline & Total length & 14 & $21.786 \pm 0.388$ & 19 & $20.312 \pm 0.502$ & $0.025^{*}$ \\
\hline & Maximum depth & 14 & $3.801 \pm 0.060$ & 19 & $3.675 \pm 0.087$ & 0.255 \\
\hline & Gonopodial length & 14 & $3.816 \pm 0.115$ & 19 & $3.871 \pm 0.124$ & 0.832 \\
\hline & Caudal fin area & 14 & $21.652 \pm 0.897$ & 19 & $19.663 \pm 1.047$ & 0.151 \\
\hline & Dorsal fin area & 14 & $6.635 \pm 0.389$ & 19 & $6.536 \pm 0.497$ & 0.881 \\
\hline & Body area & 14 & $45.829 \pm 1.529$ & 19 & $43.502 \pm 1.709$ & 0.305 \\
\hline & Total area & 14 & $74.116 \pm 2.171$ & 19 & $69.701 \pm 3.068$ & 0.252 \\
\hline & 10 dorsal scales & 14 & $4.347 \pm 0.104$ & 19 & $4.240 \pm 0.109$ & 0.524 \\
\hline
\end{tabular}


Table 2 Estimates of population-level FA in male guppies. Inbred and control values are given for 、 transformed FA $(\times 100)$ for the three colour areas. $F$ ratios were calculated to test whether inbreeding increased fluctuating asymmetry for $\sqrt{ } \mathrm{FA}$, relative FA and \%FA. No differences were significant at the $P<0.05$ level

\begin{tabular}{|c|c|c|c|c|c|c|c|c|}
\hline \multirow[b]{2}{*}{ Population } & \multirow[b]{2}{*}{ Trait } & \multicolumn{2}{|c|}{ Inbred FA } & \multicolumn{2}{|c|}{ Control FA } & \multicolumn{3}{|c|}{$F$ ratio and $P$} \\
\hline & & $N$ & FA $(\sqrt{ }$ data $)$ & $N$ & $\mathrm{FA}(\sqrt{ }$ data $)$ & $\sqrt{F A}$ & Relative FA & $\% \mathrm{FA}$ \\
\hline \multirow[t]{3}{*}{ Aripo } & Melanin & 24 & 2.211 & 23 & 2.256 & $0.98 \mathrm{NS}$ & $1.30 \mathrm{NS}$ & $0.98 \mathrm{NS}$ \\
\hline & Carotenoid & 24 & 0.527 & 23 & 0.615 & $0.86 \mathrm{NS}$ & $0.79 \mathrm{NS}$ & $0.82 \mathrm{NS}$ \\
\hline & Iridescent & 20 & 1.679 & 23 & 5.742 & $0.29 \mathrm{NS}$ & $0.88 \mathrm{NS}$ & $0.30 \mathrm{NS}$ \\
\hline \multirow{2}{*}{ Paria } & Carotenoid & 14 & 5.359 & 19 & 2.708 & $1.98 \mathrm{NS}$ & $2.16 \mathrm{NS}$ & $1.99 \mathrm{NS}$ \\
\hline & Iridescent & 9 & 5.497 & 8 & 1.895 & $3.45 \mathrm{NS}$ & $1.82 \mathrm{NS}$ & $2.96 \mathrm{NS}$ \\
\hline
\end{tabular}

trait area and body size were weak and not significant. The only significant difference between inbred and control populations was in the 'wrong' direction, with the control population having greater FA (Aripo population, iridescent $\sqrt{\mathrm{FA}} F_{22,19}=3.44$, $P<0.01$ and iridescent $\% \mathrm{FA} F_{22,19}=3.33, P<0.01$ ).

\section{Pigment areas}

Inbreeding depression for pigment area occurred in both populations. Comparisons were made using ANOVA, removing the effect of line. Inbred Aripo males had less melanin pigment than control males (inbred $1.30 \pm 0.05$, control $1.61 \pm 0.06, P<0.001$ ) and this difference remained significant when body area was taken into account (Fig. 3). There was no effect of inbreeding on iridescent or carotenoid pigments among Aripo males (all $P>0.05$ ). Inbred Paria males had reduced carotenoid pigment area and this relationship was very strong once body area was taken into account (Fig. 3). There was no inbreeding depression in melanin or iridescent pigment areas.

\section{Spot number}

Inbreeding depression was also revealed in the number of pigment spots. Comparisons were made using ordinal logistic regression, removing the effect of line. Inbred Aripo males had significantly fewer spots than control males (Fig. 4). This was accounted for by marked reductions in the number of melanin and iridescent subspots in inbred males. There was also a less pronounced reduction in the number of iridescent colours. There were no differences in spot numbers between inbred and control Paria males (all $P>0.05$ ).

\section{Spot asymmetry}

The amount of spot asymmetry differed between pigments (Table 3). The number of melanin spots on each side was highly variable and about one-third of males had at least one unmatched melanin spot (40 per cent Aripo, 30 per cent Paria). In contrast, nearly all males had equal numbers of carotenoid spots on left and right sides and very few spots were unmatched ( 6 per cent Aripo, 3 per cent Paria). In neither population was there any substantial iridescent spot asymmetry. Only one individual in the Aripo and only four in the Paria had unmatched iridescent spots. Despite this variation, none of the colour pigments showed any difference in spot asymmetry between inbred and control males in either population (Table 3 ). There was no evidence for any pigment that the number of unmatched spots correlated closely with the total number of spots (all Spearman $\rho<0.34, P>0.05$ ), so controlling for this parameter was not necessary.

\section{Discussion}

The first question addressed in this study was whether the genetic stress caused by inbreeding increased fluctuating asymmetry in sexual traits. FA was measured in three colour pigment areas (melanin, carotenoid and iridescent) from two populations of guppies (from Aripo and Paria river basins). These pigments form part of the male's sexual display and are not present in females. None of the traits in either population showed increased FA under inbreeding (Table 2). In addition, no inbreeding effect on FA was observed when controlling for mean pigment area or body area. These results follow similar outcomes from experimental studies in Drosophila (Fowler \& Whitlock, 1994) and 
bees (Clarke et al., 1992) using non-sexual traits. However, this study and that by Fowler \& Whitlock (1994) considered only mild degrees of inbreeding (one or two generations of sib-mating), and bees are unusual as they are haplodiploid and so will have been purged of deleterious recessives. Maybe these studies show that FA is subject to substantial homeostasis at low levels of inbreeding. This hypothesis will need to be investigated using a range of levels of inbreeding.

Our experiment also allowed us to reject the claim that FA was a particularly sensitive measure of genetic stress (Parsons, 1990). Although there was

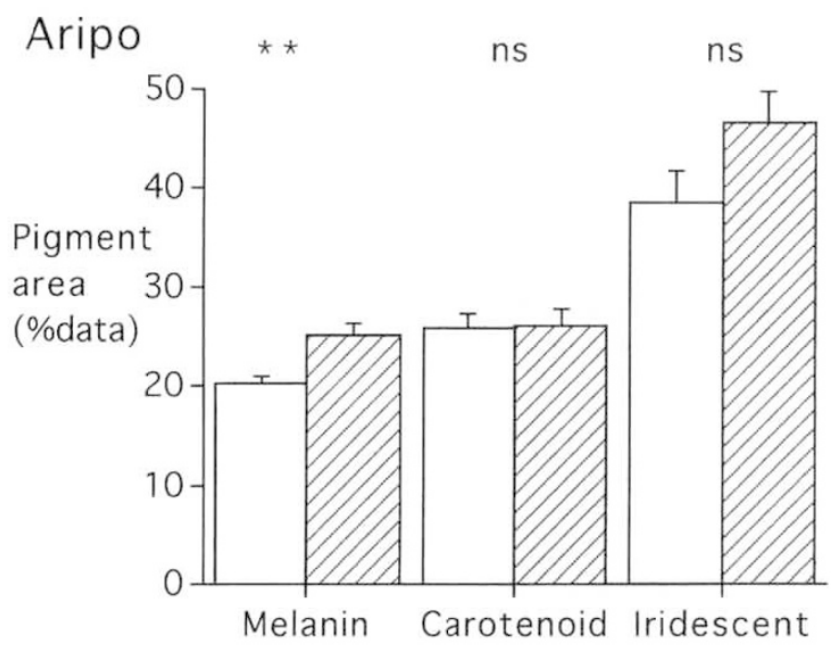

\section{Colour Pigment}

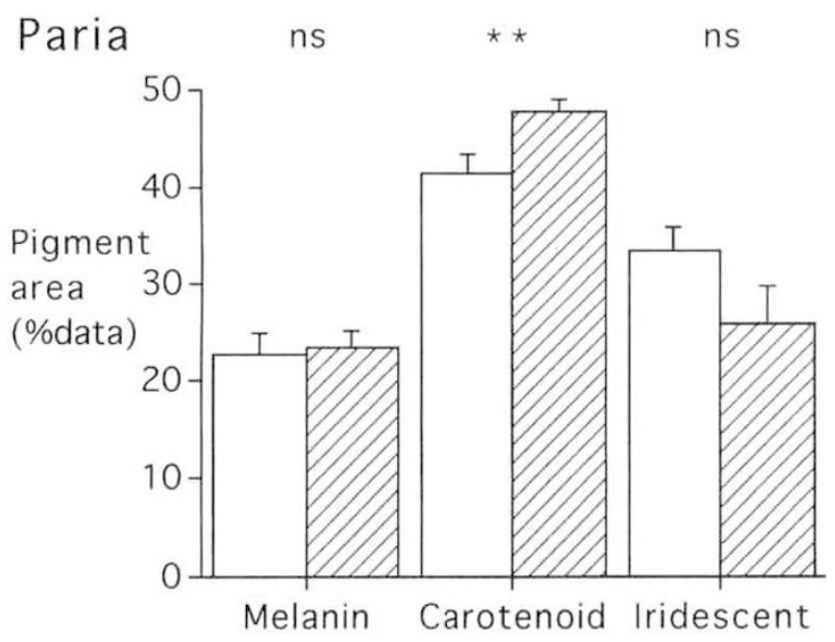

\section{Colour Pigment}

Fig. 3 Mean pigment areas expressed as a percentage of body area for inbred (clear) and control (cross-line) populations of guppies: ${ }^{* *} P<0.01$. no effect of inbreeding on FA, there were detectable differences between inbred and control lines in a number of other traits. The size of pigment areas and the number of pigment spots were smaller in inbred males (Figs 3 and 4). The effects were marked in the Aripo population, in which inbred individuals had smaller melanin pigment areas, fewer melanin spots and fewer iridescent subspots. The evidence was more equivocal for the Paria population except that inbreds had smaller carotenoid pigment areas. The difference between the populations was most likely a reflection of the greater sample size and number of inbred lines of the Aripo population.

These results serve two purposes. First, they show that inbreeding did cause detectable phenotypic differences in various aspects of male sexual coloration. Hence, the absence of a response in FA to inbreeding can not be attributed to the inbreeding regime not causing genetic stress. Secondly, they revealed that FA was less sensitive to mild inbreeding than are other measures. It is interesting to note that asymmetry in neither pigment size (i.e. FA) nor the number and position of pigment spots showed

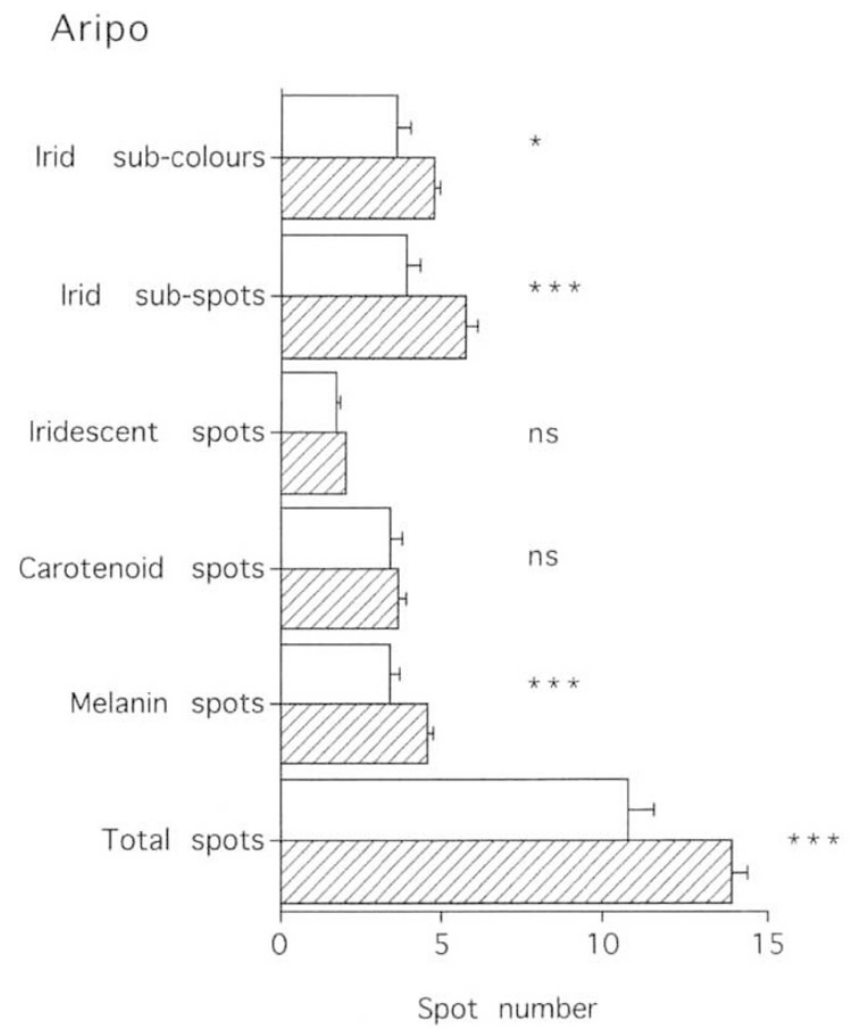

Fig. 4 Spot number summed over left and right sides in inbred (clear) and control (cross-line) Aripo guppy populations: ${ }^{*} P<0.05,{ }^{* * *} P<0.001$. 
Table 3 Spot asymmetry in inbred and control populations of male guppies. Comparison controlling for line

\begin{tabular}{|c|c|c|c|c|c|c|}
\hline \multirow[b]{2}{*}{ Population } & \multirow[b]{2}{*}{ Pigment } & \multicolumn{2}{|c|}{$\begin{array}{l}\text { Inbred } \\
\text { unmatched spots }\end{array}$} & \multicolumn{2}{|c|}{$\begin{array}{l}\text { Control } \\
\text { unmatched spots }\end{array}$} & \multirow[b]{2}{*}{$P$} \\
\hline & & $N$ & mean $\pm \mathrm{SE}$ & $N$ & mean $\pm \mathrm{SE}$ & \\
\hline \multirow[t]{4}{*}{ Aripo } & Melanin & 24 & $0.542 \pm 0.120$ & 22 & $0.500 \pm 0.157$ & 0.546 \\
\hline & Carotenoid & 24 & $0.042 \pm 0.042$ & 22 & $0.0 \pm 0.0$ & 0.970 \\
\hline & Iridescent subspots & 24 & $0.583 \pm 0.133$ & 22 & $0.182 \pm 0.084$ & 0.057 \\
\hline & Iridescent subcolours & 24 & $0.333 \pm 0.130$ & 22 & $0.091 \pm 0.063$ & 0.087 \\
\hline \multirow[t]{4}{*}{ Paria } & Melanin & 14 & $0.429 \pm 0.173$ & 19 & $0.368 \pm 0.113$ & 0.998 \\
\hline & Carotenoid & 14 & $0.214 \pm 0.114$ & 19 & $0.053 \pm 0.053$ & 0.213 \\
\hline & Iridescent subspots & 14 & $0.357 \pm 0.133$ & 19 & $0.263 \pm 0.104$ & 0.539 \\
\hline & Iridescent subcolours & 14 & $0.214 \pm 0.114$ & 19 & $0.105+0.072$ & 0.383 \\
\hline
\end{tabular}

any response to inbreeding, unlike measurements of pigment area and pigment spot number. Standard measurements of size appear to be more sensitive indicators of inbreeding than does asymmetry. This comparison of sensitivity is valid as measurements were made on the same samples using similar statistical procedures. But this does not lead to the conclusion that inbreeding cannot cause an increase in FA. Such a response might well be detectable in studies with larger sample sizes or harsher genetic stress.

The third question raised concerned female choice and whether it was directed at traits that are good at reflecting inbreeding. Our findings are in general agreement with the hypothesis. Female preference in the Paria population was strong for carotenoid but non-existent or weak for melanin or iridescent pigments (Houde, 1988a). This was paralleled by the distribution of inbreeding depression, which was strongly detected in the area of carotenoid pigment when overall body size was controlled for. There was no inbreeding depression in the other two pigment groups. Less is known about female mate preferences in the Aripo population. It is clear that females do not have strong preference for carotenoid (like other guppy populations), but it is not known whether other pigment groups are important (Houde, 1988a). In the Aripo population inbreeding depression was associated with melanin (area and spot number) and iridescent (subspot number) pigments but not with carotenoid. Overall, these findings were suggestive that female preference was directed at male traits that provide information about male genetic quality. But this conclusion can not be strongly held owing to the insufficient knowledge about female preference in the Aripo population.
The results reported here should not be taken as definitive. The analysis is based on a small sample with only a few lines per population. We controlled for line effects statistically, but it would have been better to have had a greater level of replication. This constraint is particularly severe in the Paria population, where we also combined data across two generations because of low fecundity. Greater trust will be put in the conclusions drawn here once similar studies on a larger scale have been undertaken.

\section{Acknowledgements}

Thanks to Ricardo Azevedo, Kevin Fowler and the referees who commented on an earlier draft. This work was supported by grants from the Leverhulme Trust, the Royal Society and a small grant from ASAB. The work was completed while A. P. was a Fellow of the Wissenschaftskolleg zu Berlin.

\section{References}

Andersson, M. B. 1994. Sexual Selection. Princeton University Press, Princeton, NJ.

CHARLESWORTH, D. AND CHARLESWORTH, B. 1987. Inbreeding depression and its evolutionary consequences. Ann. Rev. Ecol. Syst., 18, 237-268.

CLARKE, G. M. 1995. Relationships between developmental stability and fitness: application for conservation biology. Conserv. Biol., 9, 18-24.

Clarke, G. M., Oldroyd, B. P. AND Hunt, P. 1992. The genetic basis of developmental stability in Apis mellifera: heterozygosity vs. genic balance. Evolution, 46, $753-762$.

CUTHill, I. C., SWADDle, J. P. AND WitTer, M. S. 1993. Fluctuating asymmetry. Nature, 363, 217-218.

ENDLER, J. A. 1978. A predator's view of animal color patterns. Evol. Biol., 11, 319-364.

(c) The Genetical Society of Great Britain, Heredity, 79, 515-523. 
ENDLER, J. A. 1980. Natural selection on color patterns in Poecilia reticulata. Evolution, 34, 76-91.

FAJEN, A. AND BREDEN, F. 1992. Mitochondrial DNA sequence variation among natural populations of the Trinidad guppy, Poecilia reticulata. Evolution, 46, $1457-1465$.

FOWLER, K. AND WHITLOCK, M. C. 1994. Fluctuating asymmetry does not increase with moderate inbreeding in Drosophila melanogaster. Heredity, 73, 373-376.

HOUDE, A. E. 1988a. Genetic difference in female choice between two guppy populations. Anim. Behav., 36, $510-516$.

HOUDE, A. E. 1988b. The effects of female choice and male-male competition on the mating success of male guppies. Anim. Behav., 36, 888-896.

HOUDE, A. E. AND ENDLER, J. A. 1990. Correlated evolution of female mating preferences and male color patterns in the guppy Poecilia reticulata. Science, 248, 1405-1408. HOUDE, A. E. 1992. Sex-linked heritability of a sexually selected character in a natural population of Poecilia reticulata (Pisces: Poecilidae) (guppies). Heredity, 69, 229-235.

LEARY, R. F., ALLENDORF, F. W. AND KNUDSEN, L. K. 1984. Superior developmental stability of heterozygotes at enzyme loci in salmonid fishes. Am. Nat., 124, 540-551.

MATHER, K. 1953. Genetic control of stability in development. Heredity, 7, 297-336.

MøLLER, A. P. 1990. Fluctuating asymmetry in male sexual ornaments may reliably reveal male quality. Anim. Behav., 40, 1185-1187.

MøLlER, A. P. 1992. Female swallow preference for symmetrical male sexual ornaments. Nature, 357, 238-240.
MØLLER, A. P. AND HÖGLUND, J. 1991. Patterns of fluctuating asymmetry in avian feather ornaments: implications for models of sexual selection. Proc. R. Soc. B, 245, $1-5$.

MøLleR, A. P. AND POMIANKOWSKI, A. 1993. Fluctuating asymmetry and sexual selection. Genetica, 89, 267-279.

NICOLETTO, P. F. 1995. Offspring quality and female choice in the guppy, Poecilia reticulata. Anim. Behav., 49, 377-387.

PARSONS, P. A. 1990. Fluctuating asymmetry: an epigenetic measure of stress. Biol. Rev., 65, 131-145.

PALMER, A. R. AND STROBECK, C. 1986. Fluctuating asymmetry: Measurement, analysis, patterns. Ann. Rev. Ecol. Syst., 17, 391-421.

REEVE, E. C. R. 1960. Some genetic tests on asymmetry of sternopleural chaeta number in Drosophila. Genet. Res., $1,151-172$.

REYNOLDS, J. D., GROSS, M. R. AND COOMBS, M. J. 1993. Environmental conditions and male morphology determine alternative mating behaviour in Trinidadian guppies. Anim. Behav., 45, 145-152.

SAS InSTITUTE INC. 1996. JMP Statistical Discovery Software. Version 3.1.6. SAS Institute, Cary, NC.

SOKAL, R. R. AND RHOLF, F. J. 1995. Biometry, 3rd edn. W. H. Freeman, New York.

SOULÉ, M. E. 1979. Heterozygosity and developmental asymmetry: another look. Evolution, 33, 396-401.

SOULÉ, M. E. 1982. Allomeric variation 1. The theory and some consequences. Am. Nat., 120, 751-764.

SWADDLE, J. P. AND CuTHill, I. C. 1994a. Female zebra finches prefer symmetric males. Nature, 367, 165-166.

swaddle, J. P. AND CUThill, 1. C. 1994b. Female zebra finches prefer males with symmetrically manipulated chest plumage. Proc. R. Soc. B, 258, 267-271. 